\title{
Mechanics of the exceptional anuran ear
}

\author{
Richard L. M. Schoffelen · Johannes M. Segenhout • \\ Pim van Dijk
}

Received: 9 July 2007/Revised: 11 March 2008/Accepted: 14 March 2008/Published online: 3 April 2008

(C) The Author(s) 2008

\begin{abstract}
The anuran ear is frequently used for studying fundamental properties of vertebrate auditory systems. This is due to its unique anatomical features, most prominently the lack of a basilar membrane and the presence of two dedicated acoustic end organs, the basilar papilla and the amphibian papilla. Our current anatomical and functional knowledge implies that three distinct regions can be identified within these two organs. The basilar papilla functions as a single auditory filter. The low-frequency portion of the amphibian papilla is an electrically tuned, tonotopically organized auditory end organ. The high-frequency portion of the amphibian papilla is mechanically tuned and tonotopically organized, and it emits spontaneous otoacoustic emissions. This high-frequency portion of the amphibian papilla shows a remarkable, functional resemblance to the mammalian cochlea.
\end{abstract}

Keywords Amphibian · Anuran · Frog ·

Auditory system $\cdot$ Inner ear mechanics

\section{Introduction}

The anatomy and physiology of the amphibian ear show both remarkable resemblances and striking differences

R. L. M. Schoffelen · J. M. Segenhout · P. van Dijk Department of Otorhinolaryngology/Head and Neck Surgery, University Medical Center Groningen, P.O. Box 30001,

9700 RB Groningen, The Netherlands

R. L. M. Schoffelen $(\bowtie) \cdot$ P. van Dijk

School of Behavioral and Cognitive Neuroscience,

University of Groningen, P.O. Box 196,

9700 AD Groningen, The Netherlands

e-mail: r.l.m.schoffelen@rug.nl when compared to the mammalian auditory system. The differences between the human and the amphibian auditory system are too significant to warrant direct generalizations of results from the animal model to the human situation. However, studying hearing across species helps to understand the relation between the structure and function of the auditory organs (Fay and Popper 1999). Thus, we hope and expect that the knowledge gained about the amphibian auditory system fits into our understanding of auditory systems in general.

Over the course of history, a number of diverse amphibian species developed. Currently only three orders remain: anurans, urodeles, and caecilians. Their evolutionary relationship, as well as the evolutionary path of the individual orders, is still under debate. However, they are generally grouped into a single subclass, Lissamphibia of the class Amphibia (Wever 1985).

The ancestral lineage of amphibians separated from the mammalian lineage, approximately 350 million years ago, in the paleozoic era. Many of the important developments in the auditory systems emerged after the ancestral paths separated (Manley and Clack 2003). This implies that shared features, like the tympanic middle ear, developed independently in different vertebrate lineages.

The anurans -frogs and toads- form the most diverse order of amphibians. The living species are classified into two suborders, Archaeobatrachia and Neobatrachia (Wever 1985). Both within and between these suborders, there is a large variation in the anatomy and physiology of auditory systems. The most thoroughly studied species belong to the family Ranidae, as is reflected in the work referenced in this paper.

The hearing organs of anurans are often falsely assumed to be more primitive than those of mammals, crocodiles, and birds. The relatively simple structure and functioning 
of the amphibian ear offer an excellent possibility to study hearing mechanisms (e.g., Ronken 1990; Meenderink 2005). On the other hand, the sensitivity of the frog inner ear, which appears to be able to detect (sub)angstrøm oscillations (Lewis et al. 1985), shows that the frog ear functions as a sophisticated sensor.

While the ears of most vertebrate species contain one dedicated acoustic end organ, the frog ear has two, the amphibian papilla and the basilar papilla. ${ }^{1}$ Like in other vertebrates, these organs contain hair cells for the transduction of mechanical waves into electrical (neural) signals. In mammals, birds and lizards, the hair cells are set on a basilar membrane. The frog inner ear lacks such a flexible substrate for its sensory cells. The hair bundles of the frog's auditory organs are covered by a tectorial membrane, as they are in all terrestrial vertebrates except for some lizards species (Manley 2006).

In mammals, the mechanical tuning of the basilar membrane is the primary basis for frequency selectivity. In the absence of the basilar membrane, the frog's auditory organs must rely solely on the tectorial membrane and on the hair cells themselves for frequency selectivity.

Recently, Simmons et al. (2007) and Lewis and Narins (1999) published reviews of the frog's ear anatomy and physiology. In the current paper, we focus on the mechanics of the inner ear, specifically on the mechanics of the tectorial membrane. Only one publication exists on direct mechanical/acoustical measurements of structures in the frog inner ear (Purgue and Narins 2000a). Therefore, many of our inferences will result from indirect manifestation of inner ear mechanics, as observed in anatomical, electro-physiological and otoacoustic-emission studies. Nevertheless, these studies provide a consistent view of the mechanics of the anuran inner ear.

\section{Anatomy}

\section{Middle ear}

The ears of most terrestrial vertebrates can be divided into three principal parts: the outer ear, the middle ear and the inner ear. In mammals, the outer ear consists of a pinna and an ear canal, which terminates at the tympanic membrane. In most frog species the outer ear is absent, ${ }^{2}$ and the tympanic membrane is found in a bony ring, the tympanic annulus, in the side of the skull.

\footnotetext{
${ }^{1}$ See the section "Anatomy" for an explanation of the anatomical terms used.

${ }^{2}$ Some species, like Amolops tormotus (Feng et al. 2006), have a cavity in front of the tympanic membrane which is considered to be an ear canal and thus an outer ear.
}

The tympanic membrane defines the distal boundary of the middle ear cavity. This air-filled cavity is spanned by the ossicular chain, which serves to transfer vibrations of the tympanic membrane to the oval window of the inner ear. In the frog, the ossicular chain consists of two structures, the extra-columella and the columella (Jørgensen and Kanneworff 1998; Mason and Narins 2002a). The cartilaginous extra-columella is loosely connected to the center of the tympanic membrane. Medially, it flexibly connects to the partially ossified columella. The columella widens to form a footplate at its medial end, where it attaches to the oval window of the inner ear. Acoustic stimuli primarily enter the inner ear through the oval window.

The middle-ear's primary function is to compensate for the impedance mismatch between the air and the fluidfilled inner ear. There are two contributions to this compensation (Jaslow et al. 1988; Werner 2003). The first contribution results from the small area of the oval window relative to the area of the tympanic membrane. This causes a concentration of the external force exerted on the tympanic membrane. The second contribution involves a lever action of the columella footplate. The footplate attaches to the otic capsule along its ventral edge. This bond is suggested to be the location of the hinging point of the middle ear lever in the frog (Jørgensen and Kanneworff 1998; Mason and Narins 2002b). The lever action serves as a force amplification mechanism and contributes to the impedance matching between the outside air and the fluids in the inner ear. Both effects result in pressure amplification between the tympanic membrane and the columella footplate, thus overcoming the impedance mismatch between air and the inner-ear fluids.

An additional bony disk, the operculum, is flexibly attached to the oval window in amphibians. The presence of an operculum in anurans is unique among vertebrates. The operculum's position in the oval window can be modulated through the m. opercularis, which also connects it to the shoulder girdle.

The function of the operculum is not entirely clear. Possibly, it serves to transfer substrate vibrations to the inner ear (Lewis and Narins 1999; Mason and Narins $2002 b)$. The putative path for these vibrations includes the front limbs, the shoulder girdle and the $\mathrm{m}$. opercularis (Hetherington 1988; Wever 1985).

Alternatively, the operculum-columella system is proposed to protect the inner ear's sensory organs from excessive stimuli. This protection hypothesis takes two different forms. Wever (1985) suggests that the operculum and the columella footplate can be locked together through muscle action. In this manner, the flexibility of the connection to the oval window decreases and the input impedance increases, which in turn decreases the input signal amplitude of the pressure wave in the inner ear. It 
has also been suggested that the action of the m. opercularis could uncouple the operculum and the footplate (Mason and Narins 2002b). This would allow the operculum to move out of phase with the footplate. The out-ofphase motion could absorb part of the inner ear fluid displacement caused by the motion of the footplate. Effectively this creates an energetic by-pass and decreases the amplitude in the inner ear.

A tympanic middle ear, as described above, is considered to be the typical situation (Jaslow et al. 1988), which can be found in the family Ranidae. However, a wide range of variations in middle ear structures is found across species. In some species, a bony disk occupies the tympanic annulus rather than a membrane, for example, Xenopus leavis (Wever 1985), and there are a number of "earless" frogs. The tympanic membrane and the tympanic annulus are absent in these species. A functioning inner ear and a partial middle ear usually exist, although the middle ear cavity may be filled with connective tissue (e.g., Telmatobius exsul, Jaslow et al. 1988), or not exist at all (e.g., species in the Bombina family, Hetherington and Lindquist 1999; Wever 1985). Remarkably, some of these "earless" frogs have a mating call and exhibit neurophysiological responses (Bombina bombina, Walkowiak 1988; Atelopus, Lindquist et al. 1998) at typically auditory frequencies, which implies they have another path for the transfer of airborne sound to the inner ear (Jaslow et al. 1988), for example, through the lungs (Narins et al. 1988; Lindquist et al. 1998; Hetherington and Lindquist 1999).

\section{Inner ear}

The inner ear in the frog has two membranous windows: the oval window and the round window. As mentioned above, acoustic energy primarily enters the inner ear through the oval window. The round window is the main release point of this energy (Purgue and Narins 2000a). A similar lay-out can be found in other terrestrial vertebrates. However, the round window of the frog does not open into the middle ear as it does in mammals. Rather, it can be found in the top of the mouth cavity, under a lining of muscle tissue.

Within the inner ear, there are two intertwined membranous compartments: the perilymphatic and the endolymphatic labyrinths (see Fig. 1). The perilymphatic labyrinth connects to both the oval window and the round window. Starting at the oval window and going medially, it passes through a narrow foramen, and widens into the otic cavity, forming the periotic cistern. Continuing medially it narrows again into the periotic canal. This canal connects the periotic cistern with the perilymphatic space at the round window (Purgue and Narins 2000b).
Between the lateral perilymphatic cistern and the round window, part of the endolymphatic space can be found. The endolymphatic space also includes the semi-circular canals located dorsally from the otic system. It contains the sensory organs of hearing and balance. In the frog inner ear, there are eight sensory epithelia (Lewis and Narins 1999; Lewis et al. 1985), located as follows:

- three cristae in the semi-circular canals, which are sensitive to rotational acceleration of the head,

and one each in:

- the utricule, which detects linear acceleration,

- the lagena, which detects both linear acceleration and non-acoustic vibrations (Caston et al. 1977),

- the sacculus, which is sensitive substrate vibrations up to approximately $100 \mathrm{~Hz}$, and also detects high level low-frequency airborne sound, (Narins 1990; Yu et al. 1991)

- the amphibian papilla, which detects low-frequency acoustic stimuli (Feng et al. 1975), and

- the basilar papilla, which is sensitive to high-frequency airborne stimuli (Feng et al. 1975).

Hair cells are the sensory cells in all of these organs. Like all hair cells, these cells have a stereovillar bundle on their apical surface. Deflection of the bundle as a result of an acoustical vibration or a mechanical acceleration, initiates an ionic transduction current into the cell. This initial current causes a cascade of ionic currents, eventually resulting in the release of neurotransmitter at the basal surface of the cell. The released neurotransmitter triggers neural activity in the nerve fiber dendrites that innervate to the basal portion of the hair cell (Pickles 1988; Yost 2000; Keen and Hudspeth 2006).

As in most vertebrates, a tectorial membrane covers the sensory cells of the auditory end organ. This membrane is a polyelectrolyte gel, which lies on the stereovilli (Freeman et al. 2003). The function of the tectorial membrane is not well understood, and may vary between classes. However, since the stereovilli in most vertebrate ears connect to this membrane, it obviously plays an important role in the conduction of acoustic vibrations to the hair cells. ${ }^{3}$

\section{Basilar papilla}

The basilar papilla is found in a recess that opens into the saccular space at one end, and is limited by a thin contact membrane at the other. The contact membrane separates

\footnotetext{
${ }^{3}$ In the mamallian ear, the inner hair cells, which are the primary sensory cells, do not connect directly to the tectorial membrane. However, their deflection is presumably closely associated with the kinematics of the tectorial membrane (e.g., Nowotny and Gummer 2006).
} 
Fig. 1 Schematic drawing of a transverse section through the frog ear (adapted from Wever 1985). The division into the middle, and inner ear is indicated above the image; a selection of features is indicated in the image. The colored arrows indicate the paths of vibrational energy: green arrows represent the columellar path, red arrows the putative opercular path, and blue arrows indicate the path through the inner ear after combination of the columellar and opercular paths. The grey areas represents endolympatic fluid, dark yellow perilymphatic fluid. The green areas indicate the tectorial membranes in the papillae. (Color figure is available in the online version)

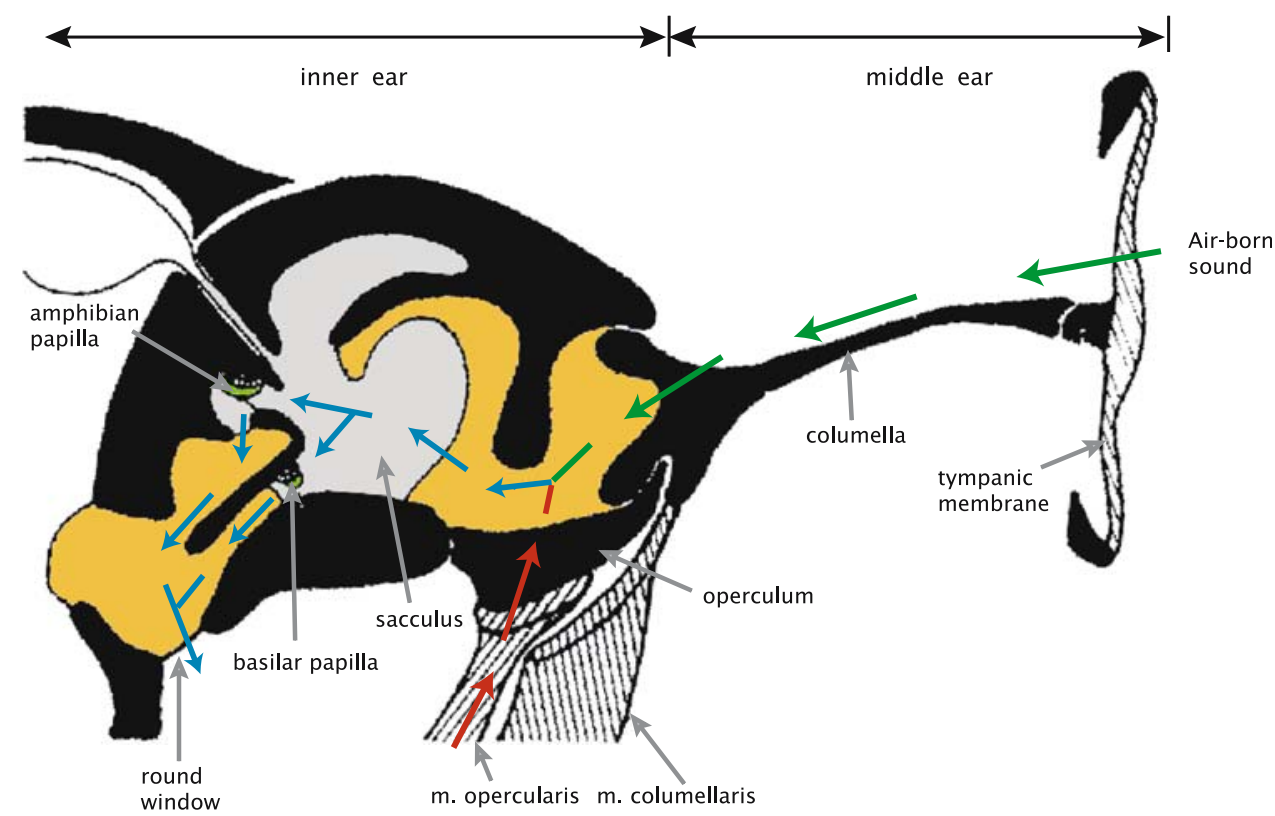

the endolymphatic fluid in the papillar recess from the perilymphatic fluid at the round window (Lewis and Narins 1999; Wever 1985). The recess perimeter is roughly oval in shape; in the bullfrog, Rana catesbeiana, its major axis is approximately $200 \mu \mathrm{m}$ long, while the minor axis measures approximately $150 \mu \mathrm{m}$ (Van Bergeijk 1957). In the leopard frog, Rana pipiens pipiens, it is of similar size (personal observation, RLMS \& JMS).

The oval perimeter of the lumen is formed from limbic tissue; a substance unique to the inner ear, and similar to cartilage (Wever 1985). The sensory epithelium is approximately $100 \mu \mathrm{m}$ long. It occupies a curved area that is symmetrical in the major axis of the elliptical lumen. It contains approximately 60 hair cells (measured in Rana catesbeiana), from which the stereovilli protrude into the lumen and connect to the tectorial membrane (Frishkopf and Flock 1974). Typically the orientation of the hair cells, as defined by the direction to which the v-shape of the stereovilli bundle points (Lewis et al. 1985), is away from the sacculus in Ranidae.

The tectorial membrane spans the lumen of the papillar recess. It occludes about half the lumen, and consequently takes an approximately semi-circular shape when viewed from the saccular side (Frishkopf and Flock 1974; Wever 1985). The membrane has pores at the surface closest to the epithelium, into which the tips of the hair bundles project (Lewis and Narins 1999). ${ }^{4}$

\footnotetext{
${ }^{4}$ Some images from the basilar papilla suggest that there are freestanding hair bundles in the anuran's basilar papilla (e.g., Lewis et al. 1985). No conclusive proof or claim of this has been reported yet.
}

Amphibian papilla

The amphibian papilla can be found in a recess, that extends medially from the saccular space and, in frogs with derived ears, bends caudally to end at a contact membrane. Like the basilar papilla's contact membrane, the membrane separates the endolymphatic fluid in the papilla recess from the perilymphatic fluid at the round window.

The sensory epithelium is set on the dorsal surface of this recess (Lewis and Narins 1999). The epithelium itself has a complex shape; it consists of a triangular patch at the rostral end, and an s-shaped caudal extension towards the contact membrane (see Fig. 2). The exact shape and length of the caudal extension varies across species, with the most elaborate extensions occurring in species of the family Ranidae (Lewis 1984), while some species lack the s-shaped extension altogether (Lewis 1981).

In the epithelium, the hair cell orientation follows a complicated pattern (see Fig. 2b). In the rostral patch the cells are orientated towards the sacculus. On the rostral half of the s-shaped extension, they are oriented along the $\mathrm{s}$-shape. However, on the caudal half, the orientation rotates $90^{\circ}$ to become perpendicular to the s-shape (Lewis 1981).

An elaborate tectorial membrane is found on the hair bundles. A bulky structure covers the rostral patch, while the membrane gets thinner along the caudal extension (Lewis et al. 1982). A tectorial curtain spans the papilla recess approximately halfway between the sacculus and the contact membrane (Shofner and Feng 1983; Wever 1985). The curtain, also called the sensing membrane (Yano et al. 1990), spans the entire cross-section of the lumen. A small slit in the tectorial curtain may function as a shunt for static fluid pressure differences (Lewis et al. 1982). 


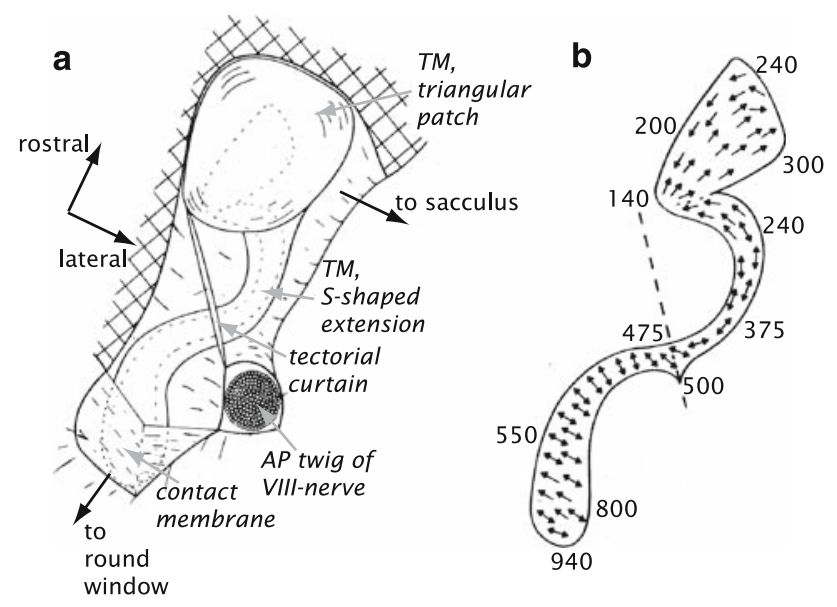

Fig. 2 Schematic drawing of the amphibian papilla of the bullfrog, Rana catesbeiana, (adapted from Lewis et al. 1982), rotated to match orientation of Fig. 1). TM Tectorial membrane, $A P$ amphibian papilla. a General overview of the AP; the dashed outline indicates the location of the sensory epithelium, b hair cell orientation in the sensory epithelium; dashed line indicates the position of the tectorial curtain. The numbers along the perimeter indicate the characteristic frequency of the auditory nerve fibers connecting to that site (in $\mathrm{Hz}$ )

\section{Response of the auditory end organs}

As mentioned in the section "Anatomy", the oval window serves as the primary entry point of acoustic energy into the inner ear; the round window presumably serves as the primary release point. After the energy passes through the oval window, it enters the periotic cistern. Between this relatively large perilymphatic space and the round window there are two possible routes: through the endolymphatic space, or through the periotic canal, bypassing the endolymphatic space and the sensory organs altogether (Purgue and Narins 2000a). The bypass presumably serves to protect the sensory organs against low-frequency over stimulation (Purgue and Narins 2000b).

The vibrational energy that ultimately stimulates the auditory end organs predominantly may enter the endolymphatic space through a patch of thin membrane in its cranial wall near the sacculus. This entry-point was identified by Purgue and Narins (2000b), by mechanically probing the perimeter of the endolyphatic space. After entering the endolymphatic space, the energy may pass either through the basilar papilla's or through the amphibian papilla's lumen to the round window.

Measurements of the motion of the respective contact membranes show that there is a frequency-dependent separation of the vibrational energy between paths through the amphibian and the basilar papilla (Purgue and Narins 2000a; see Fig. 3c). The accompagnying dynamic model of the energy flow through the bullfrog's inner ear (Purgue and Narins 2000b) indicates that this separation may occur based on the acoustic impedances of the paths.
The perilymphatic path through the periotic canal may serve as a shunt for acoustical energy to the round window. As its impedance exponentially increases with frequency, low-frequency vibrations will most effectively utilize this path. The endolymphatic path, on the other hand, presumably has a relatively constant impedance throughout the frog's auditory range. The respective lumina of the amphibian and basilar papilla have a frequency-dependent impedance of their own. According to the model mentioned above, these impedances are dominated by the characteristics of the contact membranes (Purgue and Narins) (2000b). The respective peak displacements of the contact membranes correspond to the detected frequencies in the associated organs (Purgue and Narins 2000a).

\section{Basilar papilla}

The basilar papilla's tectorial membrane is presumably driven by a vibrating pressure gradient between the the sacculus and the basilar papilla's contact membrane. No reports have been published on direct measurements of the mechanical response of the tectorial membrane, or on the basilar papilla's hair bundle mechanics. However, the hair cell orientation in the basilar papilla implies that the tectorial membrane's primary mode of motion is to and from the sacculus.

Auditory nerve fiber recordings from the frog basilar papilla show a frequency selective response (see Fig. 4 for examples of tuning curves). The range of characteristic frequencies in nerve fibers from the basilar papilla is species dependent. In the leopard frog, they are approximately between 1,200 and 2,000 Hz (Ronken 1990); in the bullfrog they are slightly lower, between 1,000 and $1,500 \mathrm{~Hz}$ (Shofner and Feng 1981; Ronken 1991). In the Hyla-family, the characteristic frequencies appear to be significantly higher; in Hyla cinerea, the green treefrog, they range from 2.8 to $3.9 \mathrm{kHz}$ (Ehret and Capranica 1980; Capranica and Moffat 1983), and in Hyla regilla roughly from 2 to $3 \mathrm{kHz}$ (Stiebler and Narins 1990; Ronken 1991). Where studied in other species, the characteristic frequencies of the basilar papilla's nerve fibers fall roughly within the bounds defined by the bullfrog at the low end and the green treefrog at the high end (Scaphiopus couchi: approximately $1-1.5 \mathrm{kHz}$, Capranica and Moffat 1975; Ronken 1991; Eleutherodactylus coqui: approximately $2-4 \mathrm{kHz}$, Narins and Capranica 1980, 1976; Ronken 1991; Physalaemus pustulosus group: around $2.2 \mathrm{kHz}$, Wilczynski et al. 2001).

In each individual frog, the tuning curves of the auditory nerve fibers appear to have a nearly identical shape and characteristic frequency (Ronken 1990; Van Dijk and Meenderink 2006). This suggests that the entire basilar papilla is tuned to the same frequency. Because of this collective tuning, characterized by one characteristic 
Fig. 3 Overview of measurements of the frog inner ear; comparison between Rana (left) and Hyla (right). The dashed lines indicate the separation between the amphibian papilla and the basilar papilla. a, b

Distributions of characteristic frequencies of auditory nerve fibers in Rana pipiens pipiens, and Hyla cinerea. c Example of the response of the contact membrane in R. catesbeiana; black line represents the amphibian papilla, open markers the basilar papilla. d, e Distributions of spontaneous otoacoustic emissions in ranid species (combined data from $R$. pipiens pipiens and $R$. esculenta), and hylid species (combined data from $H$. cinerea, $H$.

chrysoscelis, and $H$. versicolor). f Example of stimulus frequency otoacoustic emissions in $R$. pipiens pipiens at indicated stimulus levels. $\mathbf{g}, \mathbf{h}$ Examples of DP-grams measured in Rana pipiens pipiens, and Hyla cinerea. $\mathbf{a}, \mathbf{b}, \mathbf{d}, \mathbf{e}, \mathbf{g}$ and $\mathbf{h}$ are taken from Van Dijk and Meenderink (2006). There they were reproduced from Ronken (1990), Capranica and Moffat (1983), Van Dijk et al. (1989, 1996), Meenderink and Van Dijk (2004), and Van Dijk and Manley (2001), respectively. c is taken from Purgue and Narins (2000a), and $\mathbf{f}$ is an adapted presentation of data from Meenderink and Narins (2006) (graph created with data provided by Dr. Meenderink)
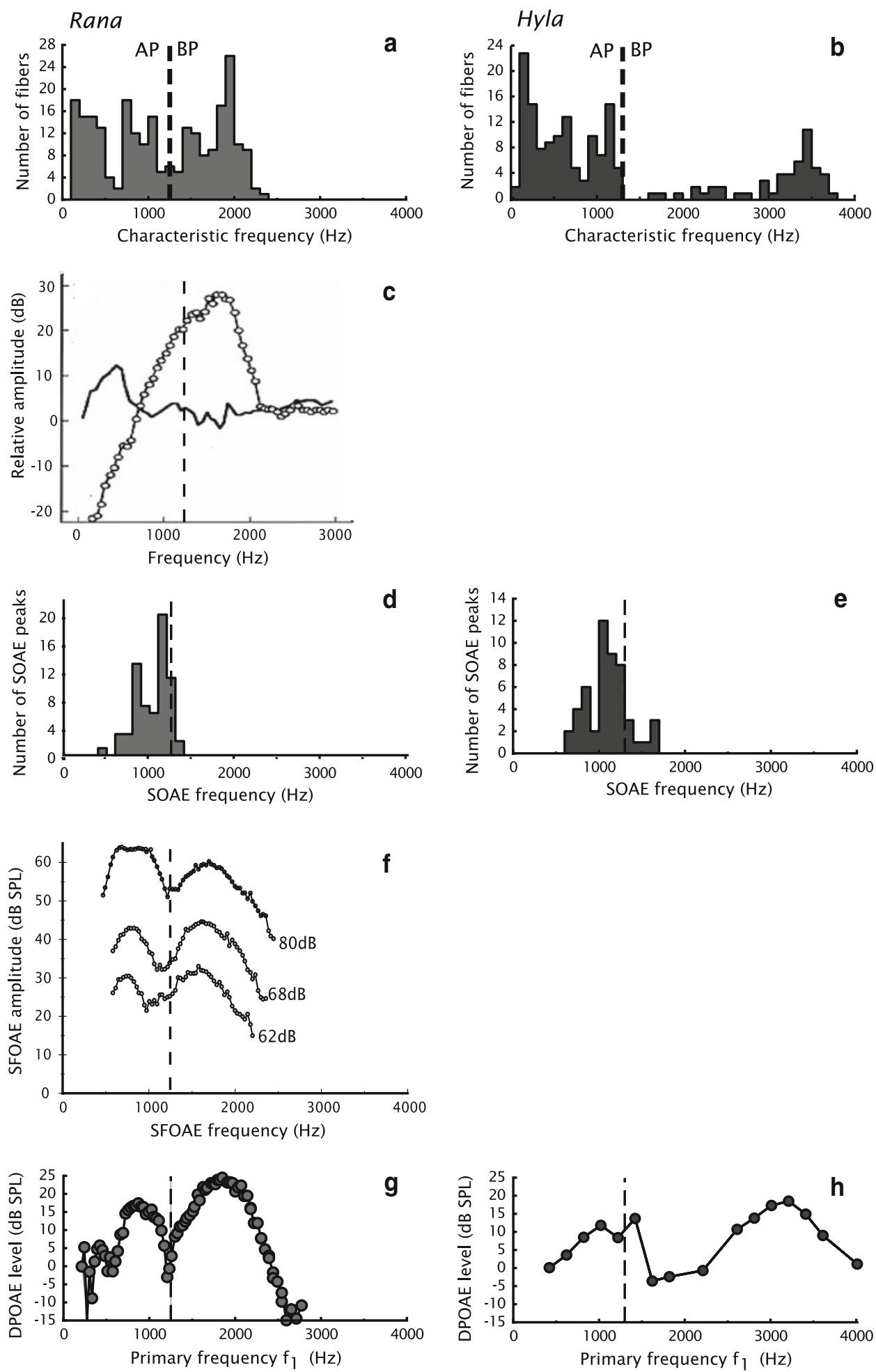

frequency and a single tuning-curve shape throughout the organ, the basilar papilla may be referred to as a "single auditory filter". In comparison, the mammalian cochlea, and the anuran amphibian papilla (see below), consist of a combination of a large number of auditory filters (Pickles 1988).
The quality factor, $Q_{10 d B}$ (e.g., Narins and Capranica 1976; Shofner and Feng 1981), is lower than that of other vertebrate hearing organs in the same frequency range, (Evans 1975; see Fig. 5), and ranges from approximately 1 to 2 in both the leopard frog and the bullfrog (Ronken 1991; see Fig. 5). For other anuran species, the ranges are somewhat 


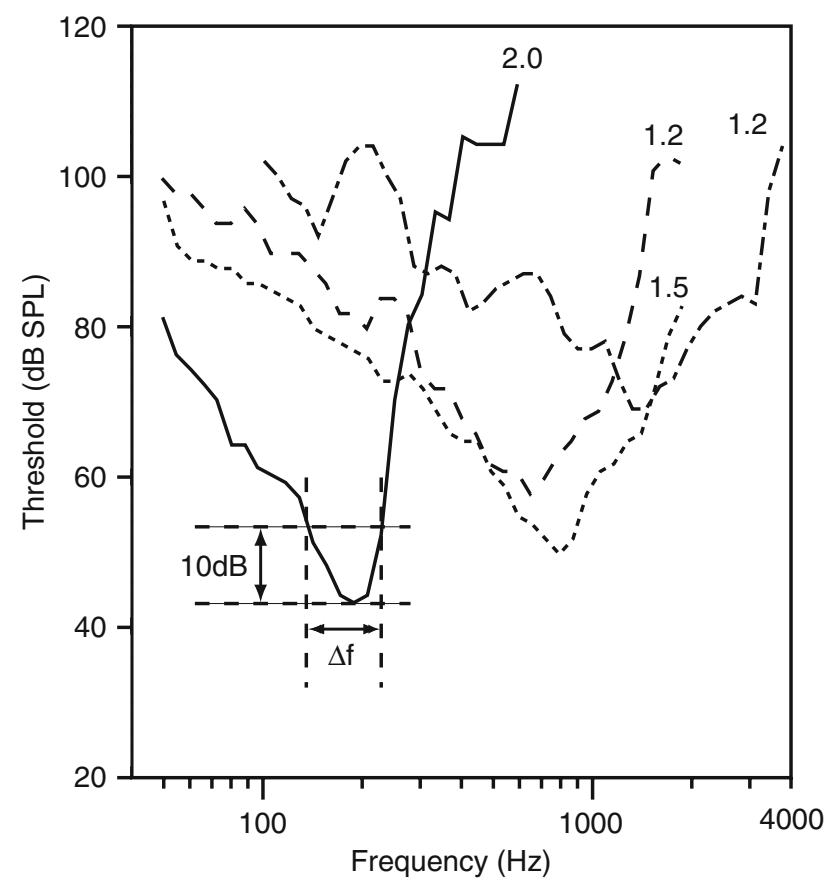

Fig. 4 Tuning curves measured in the auditory nerve in $R$. catesbeiana (unpublished measurements by JMS \& PvD, 1992; various specimens). The numbers in the graph indicate $Q_{10 \mathrm{~dB}}$ values

different, with the lowest minimum values (approximately 0.5) reported for Hyla regilla, and the highest maximum values (approximately 2.8) in Scaphiopus couchi. Thus, the basilar papilla's frequency selectivity is relatively poor.

As illustrated in Fig. 3, there is no correspondence between the range of characteristic frequencies in the basilar papilla and the range of spontaneous otoacoustic emission frequencies (Van Dijk and Manley 2001; Van Dijk and Meenderink 2006; Van Dijk et al. 2003; Meenderink and Van Dijk 2004, 2005, 2006; Meenderink and Narins 2007). Since it is generally assumed that otoacoustic emissions of a particular frequency are generated at the detection site for this frequency, this suggests that the basilar papilla does not generate spontaneous emissions. However, it does emit distortion product otoacoustic emissions (Van Dijk and Manley 2001), and stimulus frequency otoacoustic emissions (Palmer and Wilson 1982; Meenderink and Narins 2006). The peak amplitudes of the distortion product otoacoustic emissions match the characteristic frequencies of the auditory nerve fibers innervating the basilar papilla (Meenderink et al. 2005).

The amplitude and phase characteristics of the distortion product otoacoustic emissions can be qualitatively modeled by assuming the basilar papilla to be a single passive nonlinear auditory filter (Meenderink et al. 2005). Thus, nerve fiber recordings, otoacoustic emission measurements and a model based on these measurements show that the basilar papilla functions as a single frequency band auditory

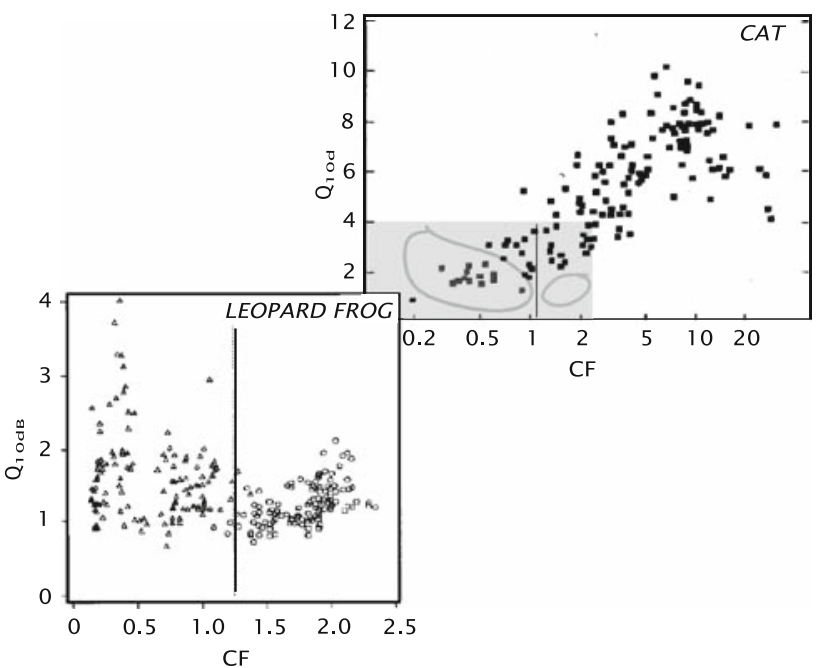

Fig. 5 Comparison of the filter quality factor $Q_{10 \mathrm{~dB}}$ versus the characteristic frequency $(\mathrm{CF}$, in $\mathrm{kHz})$ of nerve fibers from the cat cochlea (adapted from Evans 1975) and the leopard frog (adapted from Ronken 1991). In the leopard frog graph, the triangular symbols correspond to nerve fibers from the amphibian papilla; the circles to fibers from the basilar papilla. The black line indicates the upper limit of the amphibian papilla's frequency domain. The grey area in the upper (cat) graph corresponds to the area of the lower (frog) graph. The loops indicate the approximate perimeter of the fiber populations in the lower graph for the amphibian papilla and the basilar papilla.

receptor. This frequency band is relatively broad, and the center frequency may depend on species and individual animals.

The hypothesis that considers the basilar papilla as a single resonator was originally put forward by (Van Bergeijk 1957). He investigated the mechanical response of the tectorial membrane in a scale model consisting of a thin rubber tectorium spanning a lumen in a stiff wall. A number of different vibration modes existed in this model. Although Van Bergeijk's model is vastly oversimplified, the basic idea that the mechanical tuning of the tectorial membrane may be the basis of the basilar papilla's frequency selectivity is still viable.

\section{Amphibian papilla}

As in the basilar papilla, the tectorial membrane in the amphibian papilla is presumably driven by a vibrating pressure difference between the sacculus and the round window. Due to the more elaborate tectorial membrane and the more complex pattern of hair cell orientations, the motion of the membrane may be expected to be more complex than that of the basilar papilla's tectorial membrane. The tectorial curtain is in the sound path through the papilla, and presumably plays a role in conveying vibrations to the tectorial membrane and the hair bundles. 
Electrophysiological recordings from and subsequent dye-filling of single fibers of the auditory nerve show that the amphibian papilla has a tonotopic organization (Lewis et al. 1982). The fibers innervating the triangular patch have low characteristic frequencies, down to approximately $100 \mathrm{~Hz}$. The frequencies increase gradually along the caudal extension. In the bullfrog, the upper frequency is about $1000 \mathrm{~Hz}$; an overview of the tonotopic organization is given in Fig. 2b. ${ }^{5}$

The frequency selectivity of the amphibian papilla's nerve fibers is similar to that of mammalian auditory nerve fibers with the same characteristic frequency. This is in contrast to the significantly poorer frequency selectivity in the basilar papilla's nerve fibers (Ronken 1990; Evans 1975; see also Fig. 5).

In the low-frequency, rostral part of the papilla, the hair cells are electrically tuned (Pitchford and Ashmore 1987; Smotherman and Narins 1999). This tuning stems from the electrical properties of the cell membrane's ion channels. The hair cell tuning characteristics parallels the tonotopy of the single nerve recordings. Therefore, frequency selectivity in the rostral part of the amphibian papilla appears to be primarily determined by the electrical characteristics of the hair cells.

However, there is a fundamental discrepancy between the tuning characteristics of the hair cells and the auditory nerve fibers. While hair cells exhibit a second-order resonance (Pitchford and Ashmore 1987) auditory neurons display a higher order filter characteristic (Lewis 1984). Nevertheless, due to the parallels in the tonotopic organization, the assumption that the frequency selectivity is determined by the electrical tuning seems viable for the rostral part of the amphibian papilla. The higher-order responses in the neural signal may result from coupling between hair cells, which may be mechanical, for instance through the tectorial membrane.

Neurons innervating the rostral portion of the amphibian papilla display non-linear two-tone suppression similar to that in other vertebrates (Capranica and Moffat 1980; Benedix et al. 1994). Another manifestation of non-linear behavior can be found in the response to noise: secondorder Wiener kernels of low-frequency neurons show off-diagonal components, which are an indication of non-linearity (Van Dijk et al. 1994, 1997). The spectrotemporal receptive fields constructed from these Wiener kernels exhibit suppressive side bands besides the main

\footnotetext{
5 In some species of the Hyla-family the upper frequency in the amphibian papilla is markedly higher than in the bullfrog (Ronken 1991), up to approximately $2.8 \mathrm{kHz}$ in $H$. cinerea (Ehret and Capranica 1980). However, even in these species the vast majority of the recorded fibers from the amphibian papilla have best frequencies below $1250 \mathrm{~Hz}$.
}

characteristic frequency band of the fiber (Lewis and Van Dijk 2004).

Hair cells caudal to the tectorial curtain do not display electrical resonance (Smotherman and Narins 2000). Therefore, the tuning of this high-frequency, caudal region of the papilla must result from the mechanical properties of the tectorial membrane and the hair cells.

Based on the hair cell orientation, displayed in Fig. 2b, the tectorial membrane motion in the amphibian papilla is expected to be far more complex than in the basilar papilla. Assuming that the hair bundles are orientated in such a way that they are maximally deflected by the connected tectorial membrane, the rostral patch of the membrane should be moving to and from the sacculus, if the appropriate stimuli are presented. The rostral part of the s-shaped extension is moving along its major axis, whereas the extension caudal to the tectorial curtain should be moving in a transverse direction.

The amphibian papilla appears to be the only source of spontaneous otoacoustic emissions in the frog inner ear (Van Dijk et al. 1989, 1996; Long et al. 1996; Van Dijk and Manley 2001; Fig. 3d-e). The frequency distribution of these emissions corresponds to the range of best frequencies of the neurons projecting to the portion of the amphibian papilla caudal to the tectorial curtain. It is generally assumed that an otoacoustic emission of a specific frequency is generated at the location in the inner ear where that frequency is detected. Under this assumption, the presence of spontaneous otoacoustic emissions indicates that the caudal portion of the amphibian papilla exhibits spontaneous activity. Presumably, this activity is related to active amplification of input signals in this area.

The caudal region of the amphibian papilla is also involved in the generation of distortion product otoacoustic emissions (Van Dijk and Manley 2001; Meenderink and Van Dijk 2004), and stimulus frequency otoacoustic emissions (Meenderink and Narins 2006). The distortion product otoacoustic emissions from the amphibian papilla are more vulnerable to metabolic injuries than those from the basilar papilla (Van Dijk et al. 2003). Also, both the spontaneous (Van Dijk et al. 1996) and distortion product (Meenderink and Van Dijk 2006) otoacoustic emissions display a clear dependence on body temperature. These results combine to indicate that the s-shaped extension of the amphibian papilla caudal to the tectorial curtain functions as an active hearing organ.

\section{Discussion}

Our aim in this review is to outline what is known about the mechanical response properties of the amphibian and basilar papilla. Only one published report exists of the direct 
mechanical measurements of structures associated with these papillae (Purgue and Narins 2000a). The measurements show that the response of the contact membrane is frequency dependent for each papilla. The movement of the contact membrane may be assumed to reflect the fluid motion within the respective papilla. The contact membrane of the amphibian papilla shows a maximum response when the ear is stimulated with relatively low acoustic frequencies, while the basilar papilla contact membrane exhibits a maximum response to higher frequencies.

The amphibian and the basilar papilla are the only hearing organs found in terrestrial vertebrates in which the hair cells are not on a flexible basilar membrane. Instead the hair cells are embedded in a relatively stiff cartilaginous support structure. Any frequency selective response, therefore, most likely originates from the mechanical or electrical properties of the hair cells, or the mechanical properties of the tectorial membrane, or a combination of these factors. Since there are no direct mechanical measurements of either the hair cells in the papillae or the tectorial membranes, we cannot come to any definite conclusions regarding their properties. However, the available morphological and functional data allow for some hypotheses.

The most conspicuous functional characteristic of the amphibian papilla is its tonotopic organization (Lewis et al. 1982). Rostral to the tectorial curtain, the hair-cell orientation is essentially parallel to the tonotopic axis. In this low-frequency region of the amphibian papilla, the tectorial membrane apparently moves in a rostro-caudal direction. In contrast, the hair-bundle orientation suggests that the tectorial-membrane motion is perpendicular to the tonotopic axis in the high-frequency, caudal region of the papilla. The tectorial membrane's caudal end, therefore, appears to vibrate in a markedly different direction than its rostral end.

In the low-frequency region of the amphibian papilla, the hair cells display electrical tuning. The tuning properties of the hair cells parallel the tonotopic organization are measured from the afferent nerve fibers (Pitchford and Ashmore 1987). This strongly suggests that the tuning characteristics of the nerve fibers are primarily determined by the electrical hair-cell resonances. The auditory nervefiber recordings reflect the presence of high-order filtering (Lewis 1984), whereas hair cells essentially function as second-order resonances. It is, therefore, likely that coupling between the hair cells shapes the frequency responses in the nerve fibers. Such coupling may be mechanical, for example, by the tectorial membrane, or electrical, or a combination of mechanical and electrical.

Hair cells in the high-frequency, caudal region do not display any electrical resonance (Smotherman and Narins 1999). This implies that the frequency selectivity must be based on mechanical tuning, probably by the tectorial membrane. The caudal region of the amphibian papilla shares some notable characteristics with the mammalian cochlea (see also Lewis 1981):

1. the papilla is elongated, and it exhibits a tonotopic gradient along the long axis;

2. the orientation of the hair cells is perpendicular to the tonotopic axis, indicating that the hair cells are stimulated most efficiently by a deflection perpendicular to the tonotopic axis;

3. frequency selectivity, very probably, relies on mechanical tuning;

4. frequency selectivity is similar, with $Q_{10 d B^{-v a l u e s}}$ ranging from 0.8 to 2.2 ; and

5. both spontaneous and distortion product otoacoustic emissions are generated. These emissions are physiologically vulnerable.

The presence of spontaneous otoacoustic emissions shows that at least part of the amphibian papilla's caudal extension functions as an active hearing organ. In this respect it is similar to the mammalian cochlea and other vertebrate hearing organs (Lewis and Narins 1999). One active mechanism in the mammalian cochlea is the prestinmediated active somatic length changes in the outer hair cells (Brownell et al. 1985; Yost 2000; Zheng et al. 2000; Liberman et al. 2002; Dallos 2003). However, this mechanism is probably exclusively present in mammalian outer hair cells. Active hair bundle movements have been reported as an alternative active mechanism in anuran saccular hair cells (Martin and Hudspeth 1999; Martin et al. 2003; Bozovic and Hudspeth 2003); this mechanism may be present in the auditory organs as well. Although the fundamental active mechanism may differ between species, the functional result seems to be very similar across vertebrates: high auditory sensitivity and good frequency selectivity (Manley 2000).

The basilar papilla seems to function in a much simpler manner. Both neural recordings and otoacoustic emission measurements suggest that it functions as a single auditory filter. Since the hair cells in the basilar papilla are unlikely to be electrically tuned, its frequency selectivity most likely results from mechanical tuning, probably via the tectorial membrane.

The basilar papilla is remarkable in that no spontaneous otoacoustic emissions have been recorded in its frequency range. The absence of such emissions can either be caused by the fact that they are not generated within the papilla, or by the fact that the transmission of such emissions to the tympanic membrane is inhibited. However, distortion product otoacoustic emissions can be recorded in this range (e.g., Van Dijk and Manley 2001). This implies that the outward transmission is not inhibited, and therefore that 
spontaneous emissions are most likely not generated within the basilar papilla.

Furthermore, the amplitude of the basilar papilla's distortion product otoacoustic emissions depends less on temperature than that of the amphibian papilla's (Meenderink and Van Dijk 2006). Also, emissions from the basilar papilla are less sensitive to the disruption of oxygen supply (Van Dijk et al. 2003). Apparently, emissions from the basilar papilla are relatively independent of the metabolic rate, and therefore, it has been suggested that the basilar papilla is not an active hearing organ (Vassilakis et al. 2004; Van Dijk and Meenderink 2006).

In conclusion, the frog inner ear takes an exceptional place among the hearing organs of terrestrial vertebrates. It includes two auditory end organs, which both lack the basilar membrane present in every other terrestrial vertebrate species. Instead the hair cells are embedded in a relatively stiff structure. They are stimulated by the motion of the tectorial membrane. Although the basilar and amphibian papilla are similar in this respect, they appear to function by different mechanisms. In fact, even within the amphibian papilla two distinctly different functional regions can be identified. The low-frequency portion, rostral to the tectorial curtain, contains hair cells that exhibit electrical tuning. The hair cells are most sensitive to deflection along the tonotopic axis, thus this is presumably the tectorial membrane's direction of vibration. By contrast, the region caudal to the tectorial curtain shows more similarities to, for example, the mammalian cochlea: the hair cell orientation is perpendicular to the tonotopic axis, and the presence of spontaneous otoacoustic emissions suggests that it functions as an active hearing organ. Finally, the basilar papilla is yet different: it appears to function as a single passive auditory filter. Thus the frog inner ear includes two auditory end organs with three functional regions.

Acknowledgments We would like to thank Dr. JEC Wiersinga-Post for her comments on an earlier version of the manuscript. This study was supported by the Heinsius Houbolt Foundation and the Netherlands Organisation for Scientific Research, and is part of the research program of our department: Communication through Hearing and Speech. Previously unpublished data described in this paper were obtained in experiments conducted in compliance with the "Principles of animal care", publication No. 86-23, revised 1985 of the National Institute of Health, and with the current legislation, at the time of the experiments, of the country in which they were conducted (The Netherlands).

Open Access This article is distributed under the terms of the Creative Commons Attribution Noncommercial License which permits any noncommercial use, distribution, and reproduction in any medium, provided the original author(s) and source are credited.

\section{References}

Benedix Jr JH, Pedemonte M, Velluti R, Narins PM (1994) Temperature dependence of two-tone rate suppression in the northern leopard frog, Rana pipiens pipiens. J Acoust Soc Am 96:2738-2745. doi:10.1121/1.411280

Bozovic D, Hudspeth AJ (2003) Hair-bundle movements elicited by transepithelial electrical stimulation of hair cells in the sacculus of the bullfrog. Proc Natl Acad Sci USA 100:958-963. doi: 10.1073/pnas.033743310019

Brownell WE, Bader CR, Bertrand D, de Ribaupierre Y (1985) Evoked mechanical responses of isolated cochlear outer hair cells. Science 227:194-196

Capranica RR, Moffat AJM (1975) Selectivity of the peripheral auditory system of spadefoot toads (scaphiopus couchi) for sounds of biological significance. J Comp Physiol A 100:231249. doi:10.1007/BF0061453330

Capranica RR, Moffat AJM (1980) Nonlinear properties of the peripheral auditory system of anurans. In: Popper AN, Fay RR (eds) Comparative studies of hearing in vertebrates. Springer, NewYork, pp 139-165

Capranica RR, Moffat AJM (1983) Neurobehavioral correlates of sound communication in anurans. In: Ewert JP, Capranica RR, Ingle DJ (eds) Advances in vertebrate neuroethology. Plenum, New York, pp 701-730

Caston J, Precht W, Blanks RHI (1977) Response characteristics of frog's lagena afferents to natural stimulation. J Comp Physiol A 118:273-289. doi:10.1007/BF00614351

Dallos P (2003) Organ of corti kinematics. J Assoc Res Otolaryngol 4:416-421. doi:10.1007/s10162-002-3049-z

Ehret G, Capranica RR (1980) Masking patterns and filter characteristics of auditory nerve fibers in the green treefrog (Hyla cinerea). J Comp Physiol 141:1-12. doi:10.1007/ BF00611872

Evans EF (1975) Frequency selectivity at high signal levels of single units in cochlear nerve and nucleus. In: Keidel WD, Neff WD (eds) Handbook of sensory physiology, vol 5/2. Springer, New York, pp 1-108

Fay RR, Popper AN (1999) Hearing in fishes and amphibians: an introduction. In: Fay RR, Popper AN (eds) Comparative hearing: fish and amphibians, vol 11 of Springer handbook of auditory research. Springer, New York, pp 1-15

Feng AS, Narins PM, Capranica RR (1975) Three populations of primary auditory fibers in the bullfrog (Rana catesbeiana): their peripheral origins and frequency sensitivities. J Comp Physiol A 100:221-229. doi:10.1007/BF00614532

Feng AS, Narins PM, Xu C-H, Lin W-Y, Yu Z-L, Qiu Q, Xu Z-M, Shen J-X (2006) Ultrasonic communication in frogs. Nature 440:333-336. doi:10.1038/nature04416

Freeman DM, Masaki K, McAllister AR, Wei JL, Weiss TF (2003) Static material properties of the tectorial membrane: a summary. Hear Res 180:11-27. doi:10.1016/S0378-5955(03)00072-8

Frishkopf LS, Flock A (1974) Ultrastructure of the basilar papilla, an auditory organ in the bullfrog. Acta Otolaryngol 77:176-184. doi: $10.3109 / 00016487409124615$

Hetherington TE (1988) Biomechanics of vibration reception in the bullfrog, Rana catesbeiana. J Comp Physiol A 163:43-52. doi: 10.1007/BF00611995

Hetherington TE, Lindquist ED (1999) Lung-based hearing in an "earless" anuran amphibian. J Comp Physiol A 184:395-401. doi: $10.1007 / \mathrm{s} 00359005033843$

Jaslow AP, Hetherington TE, Lombard RE (1988) Structure and function of the amphibian middle ear. In: Fritzsch B, Ryan MJ, Wilczynski W, Hetherington TE, Walkowiak W (eds) The 
Evolution of the amphibian auditory system. Wiley, New York, pp 69-91

Jørgensen M, Kanneworff M (1998) Middle ear transmission in the grass frog, Rana temporaria. J Comp Physiol A 182:59-64. doi: $10.1007 / \mathrm{s} 003590050158$

Keen EC, Hudspeth AJ (2006) Transfer characteristics of the hair cell's afferent synapse. Proc Natl Acad Sci USA 103:5537-5542. doi:10.1073/pnas.060110310360

Lewis ER (1981) Suggested evolution of tonotopic organization in the frog amphibian papilla. Neurosci Lett 21:131-136. doi: 10.1016/0304-3940(81)90370-0

Lewis ER (1984) On the frog amphibian papilla. Scan Electron Microsc Pt 4:1899-1913

Lewis ER, Narins PM (1999) The acoustic periphery of amphibians; anatomy and physiology. In: Fay RR, Popper AN (eds) Comparative hearing: fish and amphibians, vol 11 of Springer handbook of auditory research. Springer, New York, pp 101-154

Lewis ER, Van Dijk P (2004) New variations on the derivation of spectro-temporal receptive fields for primary auditory afferent axons. Hear Res 189:120-136

Lewis ER, Leverenz EL, Koyama H (1982) The tonotopic organization of the bullfrog amphibian papilla, an auditory organ lacking a basilar membrane. J Comp Physiol 145:437-445. doi: 10.1007/BF00612809

Lewis ER, Leverenz EL, Bialek WS (1985) The vertebrate inner ear. CRC Press Inc, Boca Raton

Liberman MC, Gao J, He DZZ, Wu X, Jia S, Zuo J (2002) Prestin is required for electromotility of the outer hair cell and for the cochlear amplifier. Nature 419:300-304. doi:10.1038/nature01059

Lindquist ED, Hetherington TE, Volman SF (1998) Biomechanical and neurophysiological studies on audition in eared and earless harlequin frogs (Atelopus). J Comp Physiol A 183:265-271. doi: $10.1007 / \mathrm{s} 003590050254$

Long GR, Van Dijk P, Wit HP (1996) Temperature dependence of spontaneous otoacoustic emissions in the edible frog (Rana esculenta). Hear Res 98:22-28. doi: 10.1016/0378-5955(96)00057-3

Manley GA (2000) Cochlear mechanisms from a phylogenetic viewpoint. Proc Natl Acad Sci USA 97:11736-11743. doi: 10.1073/pnas.97.22.11736

Manley GA (2006) Spontaneous otoacoustic emissions from freestanding stereovillar bundles of ten species of lizard with small papillae. Hear Res 212:33-47. doi:10.1016/j.heares.2005.10.007

Manley GA, Clack JA (2003) An outline of the evolution of vertebrate hearing organs. In: Manley GA, AN Popper, RR Fay (eds) Evolution of the vertebrate auditory system, vol 22 of Springer handbook of auditory research. Springer, New York, pp $1-26$

Martin P, Hudspeth AJ (1999) Active hair-bundle movements can amplify a hair cell's response to oscillatory mechanical stimuli. Proc Natl Acad Sci USA 96:14306-14311. doi: 10.1073/pnas.96.25.14306

Martin P, Bozovic D, Choe Y, Hudspeth AJ (2003) Spontaneous oscillation by hair bundles of the bullfrog's sacculus. J Neurosci 23:4533-4548

Mason M, Narins P (2002a) Vibrometric studies of the middle ear of the bullfrog Rana catesbeiana I: the extrastapes. J Exp Biol 205:3153-3165

Mason MJ, Narins PM (2002b) Vibrometric studies of the middle ear of the bullfrog Rana catesbeiana II: the operculum. J Exp Biol 205:3167-3176

Meenderink SWF (2005) Distortion product otoacoustic emissions from the anuran inner ear. PhD Thesis, University of Maastricht, Maastricht, The Netherlands

Meenderink SWF, Narins PM (2006) Stimulus frequency otoacoustic emissions in the northern leopard frog, Rana pipiens pipiens: implications for inner ear mechanics. Hear Res 220:67-75. doi: 10.1007/s10162-006-0039-6

Meenderink SWF, Narins PM (2007) Suppression of distortion product otoacoustic emissions in the anuran ear. J Acoust Soc Am 121:344-351. doi:10.1121/1.2382458

Meenderink SWF, Van Dijk P (2004) Level dependence of distortion product otoacoustic emissions in the leopard frog, Rana pipiens pipiens. Hear Res 192:107-118

Meenderink SWF, Van Dijk P (2005) Characteristics of distortion product otoacoustic emissions in the frog from L1,L2 maps. J Acoust Soc Am 118:279-286

Meenderink SWF, Van Dijk P (2006) Temperature dependence of anuran distortion product otoacoustic emissions. J Assoc Res Otolaryngol 7:246-252. doi:10.1007/s10162-006-0039-6

Meenderink SWF, Van Dijk P, Narins PM (2005) Comparison between distortion product otoacoustic emissions and nerve fiber responses from the basilar papilla of the frog. J Acoust Soc Am 117:3165-3173. doi:10.1121/1.1871752

Narins PM (1990) Seismic communication in anuran amphibians. BioScience 40:268-274. doi:10.2307/1311263

Narins PM, Capranica RR (1976) Sexual differences in the auditory system of the tree frog Eleutherodactylus coqui. Science 192:378-380

Narins PM, Capranica RR (1980) Neural adaptations for processing the two-note call of the Puerto Rican treefrog, Eleutherodactylus coqui. Brain Behav Evol 17:48-66

Narins P, Ehret G, Tautz J (1988) Accessory pathway for sound transfer in a neotropical frog. Proc Natl Acad Sci USA 85:15081512. doi: $10.1073 /$ pnas.85.5.1508

Nowotny M, Gummer AW (2006) Nanomechanics of the subtectorial space caused by electromechanics of cochlear outer hair cells. Proc Natl Acad Sci USA 103:2120-2125. doi: 10.1073/pnas.0511125103

Palmer AR, Wilson J (1982) Spontaneous and evoked otoacoustic emissions in the frog Rana esculenta. J Physiol 324:66P

Pickles JO (1988) An introduction to the physiology of hearing, 2nd edn. Academic Press, Oxford, Great Britain

Pitchford S, Ashmore JF (1987) An electrical resonance in hair cells of the amphibian papilla of the frog Rana temporaria. Hear Res 27:75-83. doi:10.1016/0378-5955(87)90027-X

Purgue AP, Narins PM (2000a) Mechanics of the inner ear of the bullfrog (Rana catesbeiana): The contact membranes and the periotic canal. J Comp Physiol A 186:481-488. doi: $10.1007 / \mathrm{s} 003590050446$

Purgue AP, Narins PM (2000b) A model for energy flow in the inner ear of the bullfrog (Rana catesbeiana). J Comp Physiol A 186:489-495. doi:10.1007/s003590050447

Ronken DA (1990) Basic properties of auditory-nerve responses from a "simple" ear: The basilar papilla of the frog. Hear Res 47:6382. doi:10.1016/0378-5955(90)90167-N

Ronken DA (1991) Spike discharge properties that are related to the characteristic frequency of single units in the frog auditory nerve. J Acoust Soc Am 90:2428-2440. doi:10.1121/1.402047

Shofner WP, Feng AS (1981) Post-metamorphic development of the frequency selectivities and sensitivities of the peripheral auditory system of the bullfrog, Rana catesbeiana. J Exp Biol 93:181-196

Shofner WP, Feng AS (1983) A quantitative light microscopic study of the bullfrog amphibian papilla tectorium: correlation with the tonotopic organization. Hear Res 11:103-116. doi: 10.1016/0378-5955(83)90048-5

Simmons D, Meenderink S, Vassilakis P (2007) Physiology, and function of auditory end-organs in the frog inner ear. In: Narins PM, Feng AS, Fay RR, Popper AN (eds) Hearing and sound communication in amphibians, vol 28 of Springer handbook of auditory research. Springer, New York, pp $184-220$ 
Smotherman MS, Narins PM (1999) The electrical properties of auditory hair cells in the frog amphibian papilla. J Neurosci 19:5275-5292

Smotherman MS, Narins PM (2000) Hair cells, hearing and hopping: a field guide to hair cell physiology in the frog. J Exp Biol 203:2237-2246

Stiebler IB, Narins PM (1990) Temperature-dependence of auditory nerve response properties in the frog. Hear Res 46:63-81. doi: 10.1016/0378-5955(90)90140-K

Van Bergeijk WA (1957) Observations on models of the basilar papilla of the frog's ear. J Acoust Soc Am 29:1159-1162. doi: 10.1121/1.1908727

Van Dijk P, Manley GA (2001) Distortion product otoacoustic emissions in the tree frog Hyla cinerea. Hear Res 153:14-22. doi:10.1016/S0378-5955(00)00251-3

Van Dijk P, Meenderink S (2006) Distortion product otoacoustic emissions in the amphibian ear. In: Nuttall AL, Ren T, Gillespie P, Grosh K, and de Boer E (eds) Auditory mechanisms, processes and models. World Scientific, Singapore, pp 332-338

Van Dijk P, Wit HP, Segenhout JM (1989) Spontaneous otoacoustic emissions in the European edible frog (Rana esculenta): Spectral details and temperature dependence. Hear Res 42:273-282. doi: 10.1016/0378-5955(89)90151-2

Van Dijk P, Wit HP, Segenhout JM, Tubis A (1994) Wiener kernel analysis of inner ear function in the American bullfrog. J Acoust Soc Am 95:904-919. doi:10.1121/1.410009

Van Dijk P, Narins PM, Wang J (1996) Spontaneous otoacoustic emissions in seven frog species. Hear Res 101:102-112. doi: 10.1016/S0378-5955(96)00140-2

Van Dijk P, Maat A, Wit HP (1997) Wiener kernel analysis of a noise-evoked otoacoustic emissions. Br J Audiol 31:473-477
Van Dijk P, Narins PM, Mason MJ (2003) Physiological vulnerability of distortion product otoacoustic emissions from the amphibian ear. J Acoust Soc Am 114:2044-2048. doi:10.1121/1.1608957

Vassilakis PN, Meenderink SWF, Narins PM (2004) Distortion product otoacoustic emissions provide clues hearing mechanisms in the frog ear. J Acoust Soc Am 116:3713-3726. doi: $10.1121 / 1.1811571$

Walkowiak W (1988) Two auditory filter systems determine the calling behavior of the fire-bellied toad: A behavioral and neurophysiological characterization. J Comp Physiol A 164:31-41. doi:10.1007/BF00612715

Werner YL (2003) Mechanical leverage in the middle ear of the American bullfrog, Rana catesbeiana. Hear Res 175:54-65. doi: 10.1016/S0378-5955(02)00709-8

Wever EG (1985) The amphibian ear. Princeton University Press, Princeton

Wilczynski W, Rand AS, Ryan MJ (2001) Evolution of calls and auditory tuning in the Physalaemus pustulosus species group. Brain Behav Evol 58:137-151. doi:10.1159/000047268

Yano J, Sugai T, Sugitani M, Ooyama H (1990) Observations of the sensing and the tectorial membrane in bullfrog amphibian papilla: their possible functional roles. Hear Res 50:237-243. doi:10.1016/0378-5955(90)90048-T

Yost WA (2000) Fundamentals of hearing: an introduction, 4th edn. Academic Press, New York

Yu X, Lewis ER, Feld D (1991) Seismic and auditory tuning curves from bullfrog saccular and amphibian papular axons. J Comp Physiol A 169:241-248. doi:10.1007/BF0021587159

Zheng J, Shen W, He DZ, Long KB, Madison LD, Dallos P (2000) Prestin is the motor protein of cochlear outer hair cells. Nature 405:149-155. doi:10.1038/350120099 